\title{
Pengaruh Human Organization Technologi (Hot) Fit Model Terhadap Evaluasi Sistem Informasi Akademik Dosen
}

\author{
Dewi Lusiana \\ Program Studi Teknik Informatika, Fakultas Teknik, Universitas Muhammadiyah Jember \\ Email:dewilusiana@unmuhjember.ac.id
}

(Naskah Masuk: 1 Januari 2020 , Diterima Untuk Diterbitkan:15 Januari 2020)

\begin{abstract}
ABSTRAK
Sistem informasi akademik Dosen atau SIA Dosen berbasis android di Universitas Muhammadiyah Jember adalah salah satu bukti kemajuan dalam hal pelayanan dan manajemen yang lebih baik. Untuk mengetahui persepsi-persepsi yang mempengaruhi mahasiswa menggunakan Sistem Informasi Akademik berbasis android, maka diperlukan evaluasi sistem informasi yang bisa digunakan untuk evaluasi sistem informasi salah satunya yaitu HOT (Human, Organization, Technology) Fit. Teknik random sampling pada 100 responden yang telah menggunakan SIA Dosen berbasis android digunakan sebagai pengambilan sampel penelitian. Metode SEM (Structural Equation Modelling) dignakan untuk metode analisis data. Hasil penelitian QoS (Quality of Services) atau Mutu layanan member nilai positif terhadap Kenyamanan pemakai (use satisfaction). Pemakai mendapatkan layanan prima diberikan penyedia terkait yang berkoefisien 0.449 antara service quality dengan use satisfaction sedang nilai C.R 3.283. Kenyaman pemakai (use satisfaction) tidak memberi hal positif terhadap manfaat mendasar. Dikarenakan keuntungan yang diberikan SIA berbasis Android belum tentu memberikan kepuasan kepada pengguna berdasarkan nilai koefisien yaitu -0.074 kurang dari nilai syarat cukup yaitu lebih besar dari 0,5. Struktur organisasi (organization structure) berpengaruh signifikan positif terhadap net benefit. Dibuktikan dengan nilai koefisien antara organization structure dengan net benefit 0,884 juga dengan nilai C.R 4.869. Kata kunci: Model HOT-Fit, SIA
\end{abstract}

\section{ABSTRACT}

The android-based Lecturer academic information system or SIA Lecturer at the University of Muhammadiyah Jember is one of progress proof in terms of better service and management. To find out the perceptions that influence students using an Android-based Academic Information System, it is necessary to evaluate information systems that can be used to evaluate information systems, one of 
which is HOT (Human, Organization, Technology) Fit. Random sampling technique on 100 respondents who have used Android-based Lecturer SIA was used as the research sample. The SEM (Structural Equation Modeling) method was used for the data analysis method. The results of the research QoS (Quality of Services) or service quality give a positive value to user comfort (use satisfaction). Users get excellent service provided by relating providers with a coefficient of 0.449 between service quality and use satisfaction, while the value of $C . R$ is 3.283. User comfort (use satisfaction) does not give positive things to the basic benefits. Due to the benefits provided by the Android-based SIA, it does not necessarily mean that users are satisfied based on the coefficient value, which is -0.074 less than the sufficient value, which is greater than 0.5 . The organizational structure has a significant positive effect on net benefits. Evidenced by the coefficient value between the organization structure and the net benefit of 0.884 as well as the value of C.R 4.869 .

Keywords: HOT-Fit Model, SIA

\section{PENDAHULUAN}

SIA Dosen (Sistem Informasi Akademik Dosen) merupakan sistem yang buat untuk mengolah data akademis berbasis komputer, dan memberikan informasi yang berhubungan dengan akademik. Suatu lembaga pendidikan memerlukan sistem untuk menampilkan suatu informasi akademik yang terintegrasi dan manajemen administrasi yang cepat dan mudah. Lembaga yang biasanya memakai sistem ini adalah perguruan Tinggi. Perguruan tinggi adalah lanjutan dari SMA (sekolah menengah atas) atau yang sederajat diselenggarakan untuk mempersiapkan peserta didik yang mampu menerapkan dan mengembangkan ilmu pengetahuan saat menjadi anggota masyarakat.

Universitas Muhammadiyah Jember merupakan salah satu perguruan tinggi swasta yang berlokasi di Jawa Timur. Pada awal pelaksaannya, Sistem informasi akademik di Universitas Muhammadiyah Jember adalah berbasis web.Dengan digunakannya SIA Dosen tersebut penulis harapkan kegiatan administrasi dapat tertata, dikelola dengan baik dan mudah untuk mendapatkan informasi. Beberapa pelayanan yang diberikan yaitu seperti: pembuatan jadwal mata kuliah, proses penilaian, detail pembayaran, jadwal ujian.Denganseiring berkembangnya teknologi pihak pengembang berinovasi membuat sistem informasi akademik berbasis android. Diharapkan agar Dosen dapat lebih mudah untuk mendapat informasi juga mengaksesnya. Diperlukan evaluasi sistem informasi untuk mengetahui tingkat persepsi Dosen yang menggunakan SIA berbasis Android. HOT (Human, Organization, Technology) Fit adalah kerangka evaluasi yang biasa digunakan untuk mengevaluasi suatu sistem informasi. Hasil dari penelitian ini diharapkan dapat 
mengidentifikasi persepsi-persepsi yang mempengaruhi penggunaan Sistem Informasi Akademik berbasis android terhadap Dosen Universitas Muhammadiyah Jember.

\section{METODOLOGI}

Tahapan yang dilakukan untuk penelitian ini yaitu :

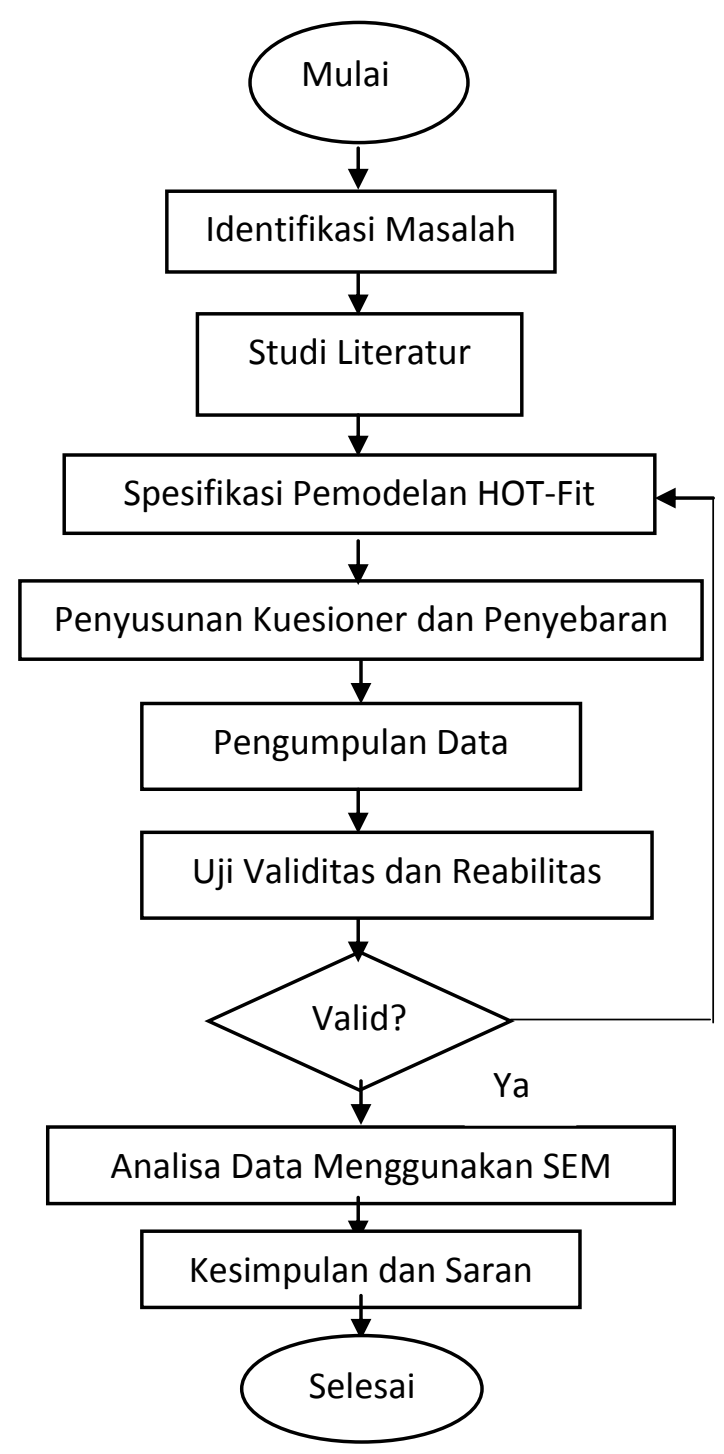

Gambar 1: Tahapan penelitian

\section{HASIL DAN PEMBAHASAN}

Responden penelitian ini adalah Dosen Universitas Muhammadiyah Jember. Setelah melakukan proses tabulasi diketahui bahwa ukuran sampel sebanyak 100 orang responden. Responden telah ditentukan dengan kriteria sampel yang sudah ditetapkan. Proses pengumpulan data melalui kuesioner, penelitian ini juga menggunakan survey observasi dan wawancara terhadap Dosen Universitas Muhammadiyah Jember untuk memperoleh informasi yang mendukung penelitian.

- Uji Validitas dan Reliabilitas Konstruk

3..1. Uji Validitas

Hasil pengujian konstruk variabel kualitas layanan (service quality), kepuasan pengguna (use satisfaction), struktur organisasi (organization structure), net benefit dapat dilihat kriteria serta nilai kritisnya pada Tabel 1.

Pada Tabel 1 dapat dilihat bahwa nilai Tidak loading factor dan Critical Rasio (CR) tertinggi dari seluruh konstruk ialah organization structure. Nilai loading factor tertinggi dari seluruh indikator pada organization structure adalah SO 3 sebesar 0,646 yang menyatakan "Implementasi SIA Dosen berbasis android telah direncanakan dengan baik oleh pihak manajemen", hal itu menunjukkan kesiapan pihak manajemen dalam segala hal yang mendukung 
keberhasilan implementasi SIA berbasis android tersebut. Sedangkan indicator dengan nilai loading factor terendah adalah SO 1 dengan nilai 0.560 yaitu "Apakah SIA berbasis Android diterapkan merupakan strategi untuk peningkatan pelayanan". Berdasarkan Analisa menggunakan metode CFA maka konstruk eksogen terbukti valid dan model tersebut memenuhi kriteria sehingga dapat lanjut ke tahapan analisa selanjutnya.

Tabel 1 Loading Factors ( $\Lambda$ ) Pengukuran Variabel Organization Structure (SO)

\begin{tabular}{|c|c|c|c|c|c|}
\hline \multicolumn{3}{|c|}{ Indikator dan Variabel } & \multirow{2}{*}{\begin{tabular}{|l} 
Loading Factor \\
0.682
\end{tabular}} & \multirow[t]{2}{*}{ C.R. } & \multirow[t]{2}{*}{$\mathrm{P}$} \\
\hline KL1 & $\mid<--$ & $\mathrm{KL}$ & & & \\
\hline KL2 & $|<--|$ & $\mathrm{KL}$ & 0.796 & 6.287 & $* * *$ \\
\hline KL3 & $<--$ & KL & 0.835 & 6.533 & $* * *$ \\
\hline KP1 & <-- & KP & 0.830 & & \\
\hline KP2 & <-- & KP & 0.511 & 2.324 & 0.020 \\
\hline NB1 & <--- & NB & 0.776 & & \\
\hline NB2 & <-- & NB & 0.836 & 8.739 & $* * *$ \\
\hline NB3 & $<---$ & NB & 0.833 & 8.424 & **** \\
\hline NB4 & $<---$ & NB & 0.805 & 8.062 & **** \\
\hline NB5 & $<--$ & NB & 0.631 & 6.156 & $* * *$ \\
\hline SO1 & $<--$ & SO & 0.560 & & \\
\hline $\mathrm{SO} 2$ & $<--$ & SO & 0.601 & 4.830 & **** \\
\hline SO3 & $<--$ & SO & 0.646 & 5.046 & $* * *$ \\
\hline SO4 & $<--$ & SO & 0.773 & 5.487 & $* * *$ \\
\hline SO5 & $|<--|$ & SO & 0.896 & 5.545 & **** \\
\hline
\end{tabular}

Semua indikator diatas dianalisis menggunakan metode CFA, sehingga indikator ini valid untuk mengukur skor variabel latennya.

\section{3..2. Uji Reliabilitas}

Nilai dari variabel penelitian yang bersifat laten telah bisa diperkirakan dengan reliabel dan valid oleh masing-masing indikatornya, dan telah bersifat interval, sehingga dengan demikian bisa dipakai untuk masukan analisis dalam persamaan struktural.

\section{Tabel 4.2 Rekap Uji Reliabilitas}

\begin{tabular}{|c|c|c|c|}
\hline No. & Variabel & $\begin{array}{c}\text { Koefisien } \\
\text { Alpha }\end{array}$ & $\begin{array}{c}\text { Keteran } \\
\text { gan }\end{array}$ \\
\hline 1. & Kualitaslayanan & 0,816 & Reliabel \\
\hline 2. & $\begin{array}{l}\text { Kepuasanpenggun } \\
\text { a }\end{array}$ & 0,631 & Reliabel \\
\hline 3. & Struturorganisasi & 0,864 & Reliabel \\
\hline 4. & Net benefit & 0,974 & Reliabel \\
\hline
\end{tabular}

- Hasil dan Analisa Structural Equition Modeling (SEM)

Ukuran sampel dalam pemodelam SEM harus memenuhi 2 macam:

1. 100 - 200 sampel (Hair, 2010), dan kedua memakai perbandingan observasi untuk setiap estimated parameter.

2. Jumlah sampel penelitian ini sebanyak 100 responden mahasiswa Universitas Muhammadiyah Jember, sehingga sampel tersebut telah memenuhi asumsi untuk dijadikan ukuran sampel.

Hasil pengujian outliers didapatkan Malhalanobis d-squared atau Mahalanobis distance. Untuk menghitung nilai Mahalanobis distance berdasarkan nilai Chi

p-ISSN : 2502-5724; e-ISSN : 2541-5735 
square pada derajat bebas 15 (didapatkan dari jumlah variabel indikator) pada tingkat $p$ $<0,01$ menggunakan rumus CHIINV $(0,01,15)=30,577$. Sehingga data yang memiliki jarak Mahalanobis distance lebih besar dari 30,577 merupakan multivariate outlier. Hasil pengujian outlier menunjukkan bahwa Mahalanobis distance dengan nilai tertinggi adalah 29,868. Hal ini menunjukkan bahwa tidak ada multivariate outlier dalam pengolahan data.

Cara pengujian tingkat asumsi normalitas yaitu dengan menghitung statistikz untuk skewness dan kurtosis data, dapat dilihat dari Critical Ratio (CR) dalam assessment of normality. Pada $\alpha=5,00$, jika nilai $C R$ dibawah nilai absolut $\pm 2,58$ data tersebut berditribusi normal, secara univariat dan multivariat (Ghozali, 2011). Data variabel-variabel penelitian, semua variabel memiliki nilai critical ratio di antara $-2,58$ sampai +2,58. Hal ini sudah bisa membuktikan terpenuhinya asumsi normalitas SEM pada masukan (input) data penelitian ini.

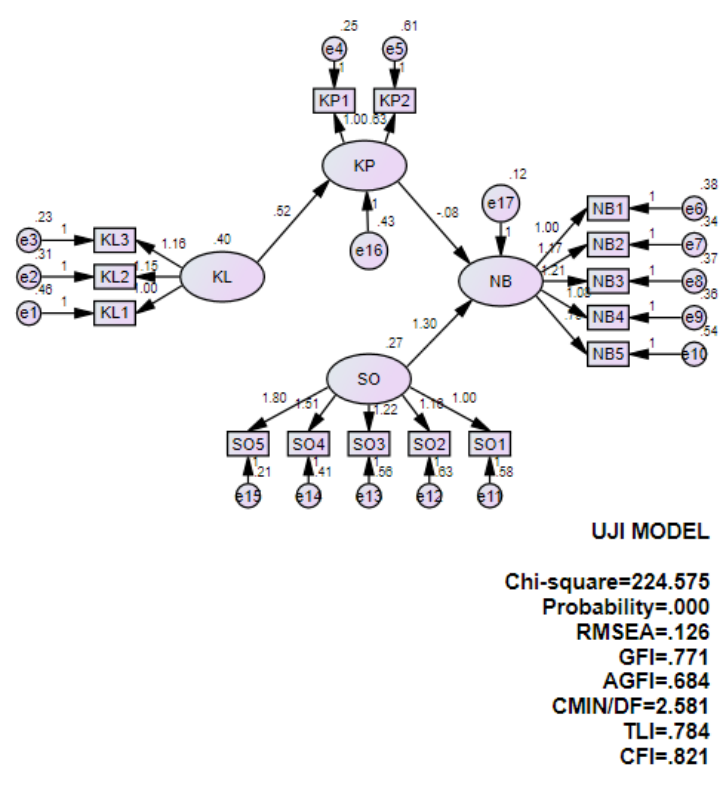

\section{Gambar 3 Model SEM}

Pada Tabel 4.3 di bawah, model tersebut terlihat nilai Chi Square dan Probability menunjukkan hasil model poor fit. sehingga, nilai tersebut lebih baik diabaikan dan melihat nilai index dari Goodness of Fit lainnya (Ghozali,2011). Dengan melihat kriteria lainnya nilai RMSEA, TLI, GFI, AGFI, dan $C F I$ yang marginal fit, sedangkan nilai dari DF/CMIN sudah memenuhi syarat menjadi good fit. Menyadur kepada prinsip parsimony (Rahayu, 2013) jika mendapati kriteria goodness of fit model satu atau lebih maka dapat dikategorikan baik dan juga sesuai dengan data dan bisa di analisis ke tahap selanjutnya. 
Tabel 4.3 Evaluasi Kriteria Goodness of Fit Indices

\begin{tabular}{cccc}
\hline $\begin{array}{c}\text { Goodness } \\
\text { of fit } \\
\text { Indices }\end{array}$ & $\begin{array}{c}\text { Cut off } \\
\text { value }\end{array}$ & $\begin{array}{c}\text { Hasil } \\
\text { Model }\end{array}$ & Keterangan \\
\hline $\begin{array}{c}\text { Chi } \\
\text { Square }\end{array}$ & $\begin{array}{c}\text { Probability } \\
\geq 0,05\end{array}$ & $\begin{array}{c}224,575 \\
(\mathrm{p}) \\
0,000\end{array}$ & Poor Fit \\
\hline CMIN/DF & $\leq 5,00$ & 2,581 & $\begin{array}{c}\text { Goodness } \\
\text { of Fit }\end{array}$ \\
\hline RMSEA & $\leq 0,08$ & 0,126 & $\begin{array}{c}\text { Marginal } \\
\text { Fit }\end{array}$ \\
\hline GFI & $\geq 0,90$ & 0,771 & $\begin{array}{c}\text { Marginal } \\
\text { Fit }\end{array}$ \\
\hline AGFI & $\geq 0,90$ & 0,684 & $\begin{array}{c}\text { Marginal } \\
\text { Fit }\end{array}$ \\
\hline TLI & $\geq 0,95$ & 0,784 & $\begin{array}{c}\text { Marginal } \\
\text { Fit }\end{array}$ \\
\hline CFI & $\geq 0,95$ & 0,821 & $\begin{array}{c}\text { Marginal } \\
\text { Fit }\end{array}$ \\
\hline
\end{tabular}

Tahapan selanjutnya setelah mengetahui hubungan antar variabel pada penelitian ini maka akan dipaparkan hasil uji hipotesis. Apabila probabilitas < 0,05 maka pengaruh variabel eksogen terhadap variabel endogen terbukti signifikan. Dan sebaliknya, apabila probabilitas > 0,05 maka pengaruh variabel eksogen terhadap variabel endogen tidak siginifikan, hal ini akan disajikan nilai koefisien jalur antar varabel signifikansi hasil uji hipotesis pada tabel 4.4 dibawah ini

Tabel 4.4 Nilai Koefisien Jalur dan

Pengujian Hipotesis

\begin{tabular}{|l|l|l|l|l|l|l|l|}
\hline \multicolumn{2}{|c|}{ Variabel } & Koefisien & CR & P & $\begin{array}{c}\text { Tingkat } \\
\text { signifikansi }\end{array}$ & Hasil Pengujian \\
\hline KP & $<-$ & KL & 0,449 & 3.283 & 0.001 & 0,05 & Signifikan \\
\hline NB & $<-$ & KP & $-0,074$ & -.797 & 0.425 & 0,05 & Sidak \\
\hline NB & $<--$ & SO & 0,884 & 4.869 & 0,000 & 0,05 & Signifikan \\
\hline
\end{tabular}

Dalam hipotesa pertama kualitas layanan (service quality) berpengaruh signifikan positif terhadap kepuasan pengguna (use satisfaction). Dari tabel diatas menunjukkan hasil probabilitas $<0,05$ yaitu sebesar 0,001. Hasil tersebut sesuai dengan hipotesis pertama yang menyatakan bahwa nilai pengaruh kualitas layanan (service quality) berpengaruh signifikan positif atau sejalan terhadap kepuasan pengguna (use satisfaction), karena pengguna merasa puas dengan adanya layanan yang cepat dan responsif. Hal ini disebabkan karena pengguna merasa puas dengan kualitas layanan yang diberikan oleh pihak manajemen.

Hasil hipotesis kedua penelitian ini menyatakan bahwa use satisfaction atau kepuasan pengguna berpengaruh tidak signifikan positif terhadap net benefit. Karena pengguna merasa manfaat yang diberikan oleh SIA berbasis android kurang memberi kepuasan kepada pengguna. Berdasarkan Tabel diatas didapatkan bahwa nilai probabilitas lebih dari 0,05 yaitu sebesar 0,425. Maka terbukti tidak signifikan.

Hipotesis ketiga dalam penelitian ini menyatakan bahwa struktur organisasi (organization structure) berpengaruh signifikan positif terhadap keuntungan bersih (net benefit). Berdasarkan Tabel diatas diketahui nilai dari probabilitasnya $<0,05$ yaitu sebesar 0,000 . Hasil tersebut sejalan 
dengan hipotesis ketiga bahwa struktur organisasi (organization structure) berpengaruh signifikan positif terhadap keuntungan bersih (net benefit). Hasil tersebut di dapatkan dari pengolahan manajemen yang baik dan juga mampu mengaplikasikan SIA berbasis android dengan cukup baik.

Rangkuman hasil penelitian hipotesis disajikan dalam Tabel 4.4 diketahui bahwa semua hipotesis dalam penelitian ini, ada tiga hipotesis seperti terlihat pada tabel 4.5

Tabel 4. 5 Ringkasan Pengujian Hipotesis

- Service quality (kualitas layanan) berpengaruh signifikan positif terhadap use satisfaction (kepuasan pengguna). Pengguna merasa mendapatkan layanan yang cepat dan responsif dari pihak terkait. Artinya semakin baik kualitas layanan pada SIA berbasis Android, maka semakin tinggi pula kepuasan pengguna terhadap SIA berbasis Android. Hal ini dibuktikan dengan nilai koefisien 0.449 antara service quality dengan use satisfaction sedang nilai C.R 3.283.

- Use satisfaction (Kepuasan pengguna)

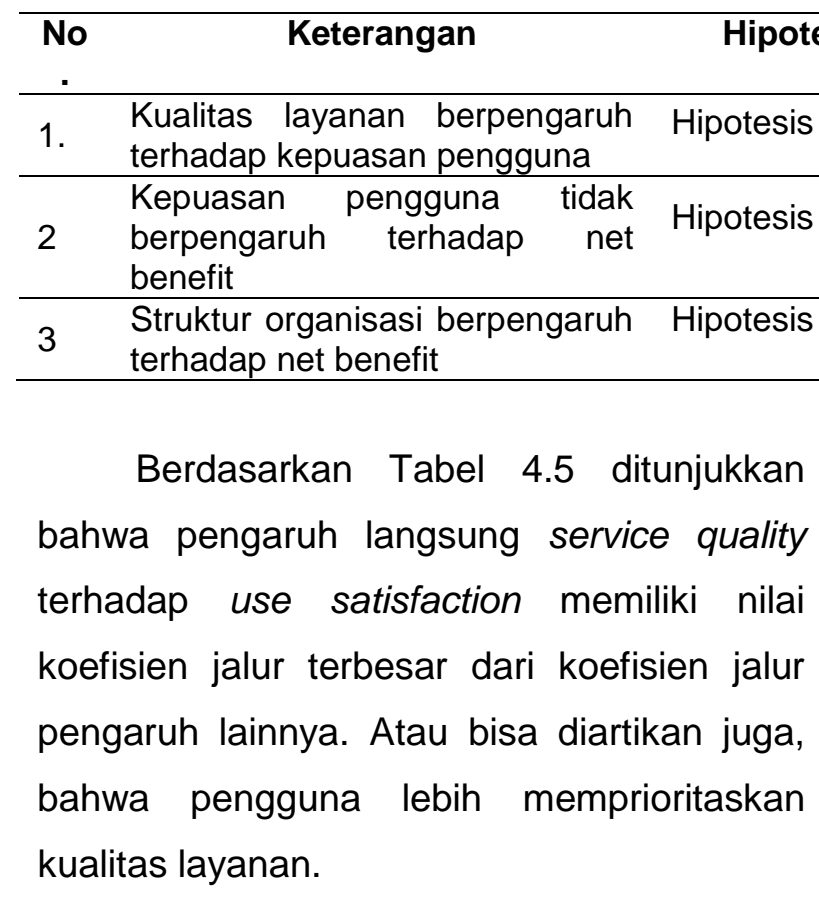

\section{KESIMPULAN}

Dari anaslisis diatas dapat disimpulkan sebagai berikut : 
berhasil dalam pengaplikasian SIA berbasis Android. Pernyataan ini dibuktikan dengan nilai koefisien antara organization structure dengan net benefit 0,884 juga dengan nilai C.R 4.869 .

\section{DAFTAR PUSTAKA}

Akhmad. (2016). Pengertian Android Yang Benar Menurut Para Ahli. Retrieved from

https://www.akhmadshare.com/2016/1 2/pengertian-android--benar--paraahli.html

Anggraeni, E. Y., \& Irviani, R. (2017). Pengantar Sistem Informasi. Yogyakarta: CV. Andi Offset.

Bahri, S., \& Zamzam, F. (2014). Model Penelitian Kuantitatif Berbasis SEMAmos. Yogyakarta: Deepublish.

Bungin, B. (2005). Metodologi Penelitian Kuantitatif. Jakarta: Kencana.

Djaali, \& Muljono, P. (2007). Pengukuran dalam Bidang Pendidikan. Jakarta: PT. Grasindo.

Erimalata, S. (2016). Pendekatan Hot-Fit Framework dalam Generalized Structural Component Analysis pada Sistem Informasi Manajemen Barang Milik Daerah: Sebuah Pengujian Efek Resiprokal. Jurnal Akuntansi Dan Investasi, 17(2). https://doi.org/10.18196/jai.2016.0051. $141-157$

Erlirianto, L. M., Ali, A. H. N., \& Herdiyanti, A. (2015). The Implementation of the Human, Organization, and TechnologyFit (HOT-Fit) Framework to Evaluate the Electronic Medical Record (EMR) System in a Hospital. Procedia Computer Science, 72. https://doi.org/10.1016/i.procs.2015.12. $\underline{166}$

Ghozali, I. (2011). MODEL PERSAMAAN STRUKTURAL KONSEP DAN APLIKASI DENGAN PROGRAM AMOS 19.0. Semarang: Badan Penerbit Universitas Diponegoro.

Hair. (2010). Multivariate Data Anaysis, Sevent Edition. Pearson Prentice Hall.

Hermawan, A. (2005). Penelitian Bisnis Paradigma Kuantitatif. Jakarta: PT. Grasindo.

Hutahaean, J. (2014). Konsep Sistem Informasi. Yogyakarta: Deepublish.

Kodarisman, R., \& Nugroho, E. (2013). Evaluasi Penerapan Sistem Informasi Manajemen Kepegawaian (SIMPEG) di Pemerintah Kota Bogor. Jurnal Nasional Teknik Elektro Dan Teknologi Informasi UGM, 2(2).

Kurniawan, A. (2009). Belajar Mudah SPSS untuk Pemula. Yogyakarta: MediaKom. Kurniawan, R., \& Yuniarto, B. (2016). Analisis Regresi. Jakarta: Kencana.

p-ISSN : 2502-5724; e-ISSN : 2541-5735 
Poluan, F., Lumenta, A., \& Sinsuw, A. (2014). Evaluasi Implementasi Sistem E-Learning Menggunakan Model Evaluasi HOT FIT Studi Kasus UNIVERSITAS SAM RATULANGI. EJournal Teknik Informatika, 4(2).

Raharjana, I. K. (2017). Pengembangan Sistem Informasi Menggunakan Metodologi Agile. Yogyakarta: Deepublish.

Santoso, S. (2007). Student Guide Series. Jakarta: PT. Elex Media Komputindo.

Santoso, S. (2011). Structural Equation Modeling (Konsep dan Aplikasi dengan AMOS 18). Jakarta: PT. Elex Media Komputindo.

Siyoto, S., \& Sodik, M. A. (2015). Dasar Metodologi Penelitian. Yogyakarta: Literasi Media Publishing.

Supranto. (2000). Statistik: Teori dan Aplikasi. Jakarta: Erlangga.

Suryani, \& Hendryadi. (2016). Metode Riset Kuantitatif: Teori dan Aplikasi pada Penelitian Bidang Manajemen dan Ekonomi Islam. Jakarta: Prenada Media.

Umar, H. (2002). Metode Riset Bisnis. Jakarta: PT. Gramedia Pustaka Utama.

Widi, R. (2011). Uji Validitas dan Reliabilitas dalam Penelitian Epidemiologi Kedokteran Gigi. Laboratorium IImu Kesehatan Gigi Dan Mulut Dan
Pencegahan Fakultas Kedokteran Gigi Universitas Negeri Jember, 8. 